\title{
Lysophosphatidylcholine induces cytotoxicity/apoptosis and IL-8 production of human endothelial cells: Related mechanisms
}

\author{
Mei-Chi Chang ${ }^{1,2}$, Jang-Jaer Lee ${ }^{3, *}$, Yi-Jane Chen ${ }^{3}$, Szu-I Lin ${ }^{4}$ Li-Deh Lin ${ }^{3}$, Eric Jein- \\ Wen Liou' ${ }^{2}$, Wei-Ling Huang ${ }^{5}$, Chiu-Po Chan ${ }^{2, *}$, Chi-Chia Huang ${ }^{6}$ and Jiiang-Huei Jeng ${ }^{3}$ \\ ${ }^{1}$ Biomedical Science Team, Chang Gung University of Science and Technology, Kwei-Shan, Taoyuan City, Taiwan \\ ${ }^{2}$ Department of Dentistry, Chang Gung Memorial Hospital, Taipei, Taiwan \\ ${ }^{3}$ School of Dentistry and Department of Dentistry, National Taiwan University Medical College and National Taiwan University \\ Hospital, Taipei, Taiwan \\ ${ }^{4}$ Department of Dentistry, Municipal Taoyuan Hospital, Taoyuan City, Taiwan \\ ${ }^{5}$ Department of Dentistry, Chang Gung Memorial Hospital, Kaohsiung, Taiwan \\ ${ }^{6}$ Department of Dentistry, Cardinal Tien Hospital, New Taipei City, Taiwan \\ *These authors contributed equally to this work
}

Correspondence to: Jiiang-Huei Jeng, email: jhjeng@ntu.edu.tw

Keywords: apoptosis; atherosclerosis; cell cycle; cytotoxicity; endothelial cells

Received: October 07, $2017 \quad$ Accepted: October 29, $2017 \quad$ Published: November 10, 2017

Copyright: Chang et al. This is an open-access article distributed under the terms of the Creative Commons Attribution License 3.0 (CC BY 3.0), which permits unrestricted use, distribution, and reproduction in any medium, provided the original author and source are credited.

\section{ABSTRACT}

Increased levels of oxidized low-density lipoprotein oxLDL) are shown to elevate the risk of cardiovascular diseases such as atherosclerosis, thrombosis, stroke, and myocardial infarction. This is possibly due to the toxic effects of oxLDLs on vascular cells. Various oxLDLs including lysophosphatidylcholine (LPC) and 7-ketocholesterol injure vascular endothelial cells and stimulate inflammatory reaction. However the toxicity of LPC on endothelial cells is not clear. In this study, human endothelial cells were exposed to LPC. Cytotoxicity was measured by 3-[4,5-dimethylthiazol-2-yl]2,5-diphenyltetrazolium bromide assay. Propidium iodide (PI) staining or PI/Annexin $V$ dual staining flow cytometry were used to determine cell cycle progression and apoptosis. Reactive oxygen species (ROS) level was analyzed by DCFH-DA labeling flow cytometry. RNA and protein expression of endothelial cells was studied by reverse transcriptase-polymerase chain reaction and western blotting. IL-8 secretion was measured by enzyme-linked immunosorbant assay. LPC showed cytotoxicity to endothelial cells $(>50 \mu \mathrm{g} / \mathrm{ml}$ ). LPC induced cell cycle arrest and apoptosis with concomitant inhibition of cdc2 and cyclin B1 expression. LPC stimulated intracellular ROS production and ATM/Chk2, ATR/Chk1 and Akt activation. IL-8 expression and secretion in endothelial cells were induced by LPC. LPC-induced apoptosis, and IL-8 expression/secretion was attenuated by LY294002, a PI3K/Akt inhibitor. These results reveal that LPC is involved in the pathogenesis of atherosclerosis and vascular diseases by stimulation of inflammation and injury to endothelial cells. These events are related to ROS, ATM/Chk2, ATR/Chk2 and PI3K/Akt signaling. Understanding the toxic mechanisms of LPC is useful for future prevention and treatment atherosclerosis.

\section{INTRODUCTION}

Cardiovascular diseases (stroke, myocardial infarction etc.) are the major systemic diseases of peoples in the world. This is possibly due to increased levels of oxidized low-density lipoprotein
(oxLDL) that elevate the risk of cardiovascular diseases. Oxidized low-density lipoprotein (Ox-LDL) contains mainly lysophosphatidylcholine (LPC), lipid ester-bound aldehydes, 7-ketocholesterol (7KC), 7 $\alpha$-hydroxycholesterol, 7 $\beta$-hydroxycholesterol, $5 \alpha, 6 \alpha-\quad$ epoxycholesterol, $5 \beta, 6 \beta$-epoxycholesterol, 
25-hydroxycholesterol, (25R)-26- hydroxycholesterol), and cholesta-3,5-dien-7-one [1]. These ox-LDLs show differential toxic effects toward vascular smooth muscle cells, endothelial cells and macrophages [2]. LPC is one major oxLDL involved in many diseases. LPC and oxidized non-esterized fatty acids are also generated by lipoprotein-associated phospholipase A2 (Lp-PLA2) and linked to the pathogenesis of atherosclerosis, myocardiac infarction, and stroke. LPC also modulates various diseaserelated mechanisms and is involved in many diseased processes including diabetes, obesity, atherosclerosis and cancer [3]. LPC has been shown to induce apoptosis of human coronary artery smooth muscle cells via activation of TRPC1/TRPC3 channels, calcium influx, Bax and caspase- 3 and contributes the atherosclerosis and coronary artery disease [4]. LPC also has the ability to impair endothelium-dependent vasorelaxation, enhance endothelial proliferation and permeability, induce adhesion and activation of lymphocytes, initiate macrophage chemotaxis and stimulate the activities of vascular smooth muscle cells and platelets [5]. Therefore targeting therapy against Lp-PLA2 and LPC are recently recommended for treatment of associated diseases [6].

Inflammatory cell infiltration of vascular walls, reactive oxygen species (ROS) production, and apoptosis of endothelial cells are involved in the pathogenesis of atherosclerosis. Oxidative stress may stimulate inflammatory response of endothelial cells by inducing the release of various cytokines such as interleukin-1 (IL-1), tumor necrosis factor- $\alpha$ (TNF- $\alpha$ ), IL-6, IL-4, chemokines and cell adhesion molecules (e.g., intercellular adhesion molecule-1 [ICAM-1], E-selectin etc.), leading to infiltration of inflammatory cells through endothelial cells into tissue and contributing to atherosclerosis [7]. LPC, as one major ox-LDL, has been shown to induce monocyte chemotactic protein-1 (MCP-1), IL-6 expression and cytotoxicity/apoptosis to endothelial cells via Notch signaling [8]. LPC also induces IL-6 and IL-8 production in endothelial cells [9]. LPC markedly inhibited nitric oxide (NO) production, but increased the levels of ROS, and maelic dialdehyde of endothelial cells [10].

Level of ROS in tumor tissues and atherosclerotic tissues is generally higher than healthy tissues [11]. The sources of ROS in endothelial cells are derived mainly from NADPH oxidase, xanthine oxidase, arachidonic acid (AA) metabolism or mitochondrial electron transfer. LPC has been shown to be the ROS inducer in endothelial cells [12-15] and may induce oxidative DNA damage and gene hypomethylation in cholangiocytes [16]. ROS and DNA damage may stimulate ataxia-telangiectasia mutated (ATM)/checkpoint kinase-1 (Chk2) and ATM and RAD3related (ATR)/Chk1 to regulate cell cycle progression and induce apoptosis [17-19]. Moreover, ROS may provoke phosphoinositide 3-kinase (PI3K)/protein kinase B (Akt) signaling to mediate inflammatory response [20]. Antioxidants and NADPH oxidase inhibitor - diphenylene iodonium (DPI) effectively suppress the IL-4-induced ROS production, IL-6 and MCP-1 secretion of endothelial cells [7].

We hypothesized that LPC generated by oxidation of LDL or by Lp-PLA2 etc. may contribute to cardiovascular diseases via inducing injury, ROS production and inflammatory mediators' production in vascular endothelial cells. We therefore designed this study to evaluate the effect of LPC on cytotoxicity, cell cycle progression, apoptosis, ROS and IL-8 production, and related signal transduction pahways (ATM/Chk2, ATR/Chk1, and PI3K/Akt) in vascular endothelial cells.

\section{RESULTS}

\section{Cytotoxicity of LPC to endothelial cells}

Lysophosphatidylcholine (LPC) showed cytotoxicity to Eahy926 (EAHY) endothelial cells. Evident cytotoxicity of LPC was noted at concentrations higher than $50 \mu \mathrm{g} /$ $\mathrm{ml}$ with a fifty percent inhibitory concentration (IC50) of about $50.73 \mu \mathrm{g} / \mathrm{ml}$ (Figure 1).

\section{Induction of cell cycle arrest and apoptosis of endothelial cells by LPC}

LPC also induced cell cycle arrest and apoptosis of EAHY endothelial cells. LPC induced G2/M cell cycle arrest of endothelial cells, at a concentration of $50 \mu \mathrm{g} /$ $\mathrm{ml}$ (Figure 2A). The apoptotic population (sub-G0/G1 population) increased by LPC at concentrations of 40 and $50 \mu \mathrm{g} / \mathrm{ml}$ (Figure 2B).

\section{Induction of apoptosis of endothelial cells by LPC}

LPC also induced apoptosis of endothelial cells at concentrations higher than $30 \mu \mathrm{g} / \mathrm{ml}$ as analyzed by PI + Annexin V flow cytometric analysis. Increase in upper right (late apoptosis) and lower right (early apoptosis) population of endothelial cells was observed by $50 \mu \mathrm{g} / \mathrm{ml}$ LPC (Figure 3A, 3B).

\section{Effect of LPC on cell cycle-related protein expression of endothelial cells}

Western blotting analysis showed that exposure of EAHY cells to LPC inhibited cdc 2 and cyclin B1 protein expression (Figure 3C), a possible reason for induction of $\mathrm{G} 2 / \mathrm{M}$ phase arrest and apoptosis.

\section{Stimulation the p-ATM, p-ATR, p-chk1, and p-chk2 protein expression of EAHY cells by LPC}

LPC induced ATM and ATR phosphorylation of endothelial cells as revealed by an increase in FITC 
(green) and TRITC (red) fluorescence, respectively (Figure 4A, 4B). Similarly, LPC also stimulated p-Chk1 and p-Chk2 phosphorylation of endothelial cells (red fluorescence, Figure 4C, 4D).

\section{Effect of LPC on IL-8 secretion and expression of endothelial cells}

LPC markedly induced IL-8 expression of endothelial cells (Figure 5A). Moreover, LPC further stimulated the production of IL- 8 in endothelial cells as analyzed by ELISA. Concentration of IL- 8 in the culture medium was stimulated from $58.8 \mathrm{pg} / \mathrm{ml}$ (control) to 119.2, 219.7 and $206.9 \mathrm{pg} / \mathrm{ml}$, by 20,40 and $60 \mu \mathrm{g} / \mathrm{ml}$ of LPC respectively (Figure 5B). In consistent, LPC also induced IL-8 protein expression of endothelial cells as studied by western blotting (Figure 5C).

\section{LPC induces ROS production and Akt phosphorylation of endothelial cells}

LPC provoked ROS production of endothelial cells as analyzed by 2',7'-Dichlorodihydrofluorescin (DCF) fluorescence flow cytometric analysis. Relative DCF fluorescence value of endothelial cells increased from 101 (control) to $124(40 \mu \mathrm{g} / \mathrm{ml} \mathrm{LPC})$ (Figure 6A). Quantitatively LPC $(40-50 \mu \mathrm{g} / \mathrm{ml})$ stimulated ROS production of endothelial cells with an increase in cellular DCF fluorescence (Figure 6B). Immunofluorescent staining study also revealed the stimulation of Akt phosphorylation of endothelial cells by LPC, as shown by an increase in p-Akt (red) fluorescence (Figure 6C).

\section{Role of PI3K/Akt signaling on LPC-induced apoptosis and IL-8 expression of endothelial cells}

Interestingly, LY294002 (a PI3K/Akt signaling inhibitor) attenuated the LPC-induced apoptosis of endothelial cells as shown by PI and annexin V dual fluorescent flow cytometry (Figure 7A). The percentage of pro-apoptotic cells (LR) and apoptotic (UR) cells decreased obviously after pretreatment and co-incubation of LPC with LY294002. Consistently LY294002 prevented the LPC-stimulated increase of IL- $8 \mathrm{mRNA} /$ protein expression and secretion in endothelial cells (Figure 7B, 7C, 7D).

\section{DISCUSSION}

Oxidized low density lipoproteins (oxLDL) such as LPC, 7-KC, 7 $\alpha$-hydroxycholesterol, $7 \beta$-hydroxycholesterol, $5 \alpha, 6 \alpha$ - epoxycholesterol, etc. may increase the risk of various cardiovascular diseases including atherosclerosis, thrombosis, stroke, myocardial infarction etc [1]. This is possibly due to toxic effects by various ox-LDLs toward vascular smooth muscle cells, endothelial cells and macrophages [2]. LPC may impair endothelium-dependent vasorelaxation, enhance endothelial proliferation and permeability, induce adhesion and activation of lymphocytes, initiate macrophage chemotaxis and modulate the activities of vascular smooth muscle cells and platelets [5]. LPC $(5-10 \mu \mathrm{g} / \mathrm{ml})$ stimulates proliferation, but induces apoptosis $(50-300 \mu \mathrm{g} /$ $\mathrm{ml}$ ) of endothelial cells via NADPH-dependent superoxide production $[14,15]$. In this study, LPC was also shown

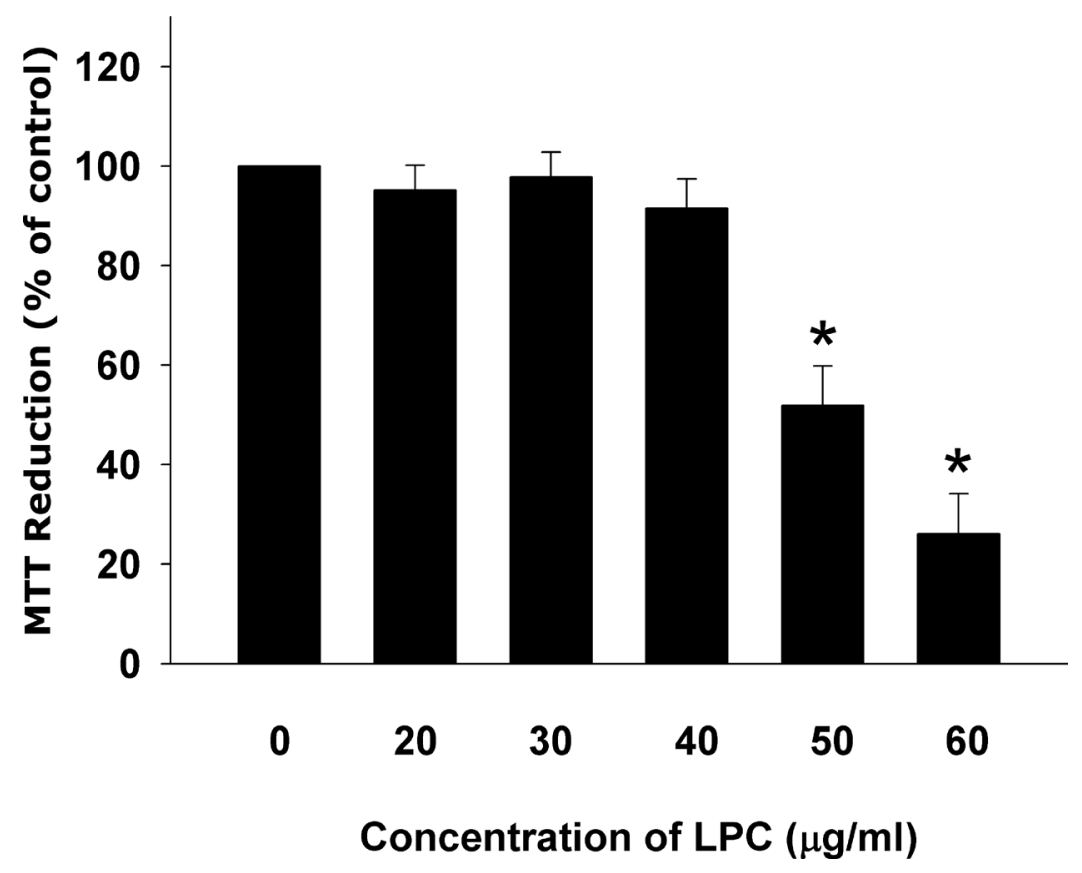

Figure 1: Cytotoxicity of LPC to endothelial cells as analyzed by MTT. Results were expressed as Mean \pm SE. "denotes statistically significant difference $(p<0.05)$ when compared with solvent control. 
to suppress endothelial cell proliferation and exhibited cytotoxicity. The dual effects of LPC on proliferation and apoptosis of endothelial cells depend on concentration and exposure time [15]. By toxic damage to endothelial cells, LPC may increase the permeability of endothelium and expose of underlying collagen to promote platelet aggregation/thrombosis.

The toxic effect of LPC is possibly related to its induction of cell cycle arrest and apoptosis of endothelial cells. In this study, LPC obviously induced G2/M and $\mathrm{S}$ - cell cycle arrest and apoptosis of endothelial cells. Similarly LPC stimulates apoptosis of HUVEC endothelial cells via NADPH-dependent superoxide production [14, 15] and H19-7 neuroprogenitor cells through the upregulation of FasL expression and activation of NF-kB [21]. Zhou et al. (2006) shows that LPC induces mainly necrosis of endothelial cells, whereas $7-\mathrm{KC}$ induces endothelial cell apoptosis [22]. These differential results
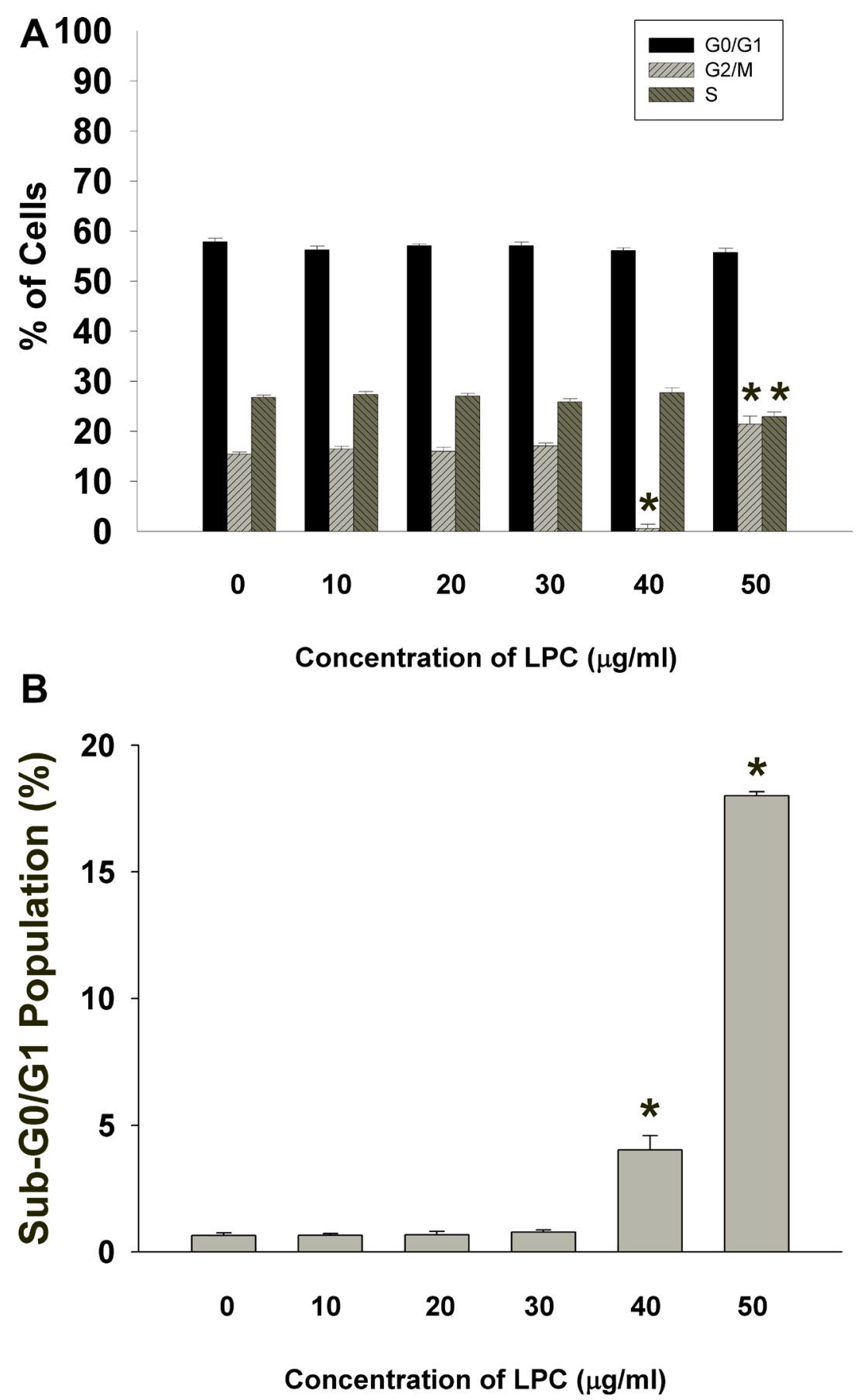

Figure 2: PI fluorescence of EAHY cells after exposure to different concentrations of LPC (10-50 mg/ml). (A) EAHY cell populations residing in G0/G1, S, and G2/M after exposure to LPC, (B) Sub G0/G1 population of EAHY cells after exposure to LPC. Results were expressed as Mean \pm SE. *indicates statistically significant difference when compared with solvent control-treated group. 
of LPC are possibly related to concentrations, exposure time, cell types etc. In this study, the induction of cell cycle arrest can be partly explained by the decrease of cdc2 and cyclin B1 expression in endothelial cells by LPC. The G2/M phase of cell cycle is critically regulated by cdc2, cyclin B1 and p21 [23, 24]. However, limited information is known about the effect of LPC on cell cycle-related proteins and more studies are needed to clarify these points.

Little is known about the effect of LPC on ATM/ Chk2 and ATR/Chk1, two check-point kinase signaling pathways to mediate ROS and DNA damage responses for control of cell cycle progression [17-19]. In this study, we further studied and intriguingly found the activation of p-ATM/p-Chk2 and p-ATR/p-Chk1 of endothelial cells by LPC, implicating the possible ROS overproduction and DNA damage response. Toxic chemicals may induce transcription, cell cycle arrest, apoptosis, cellular senescence and DNA repair via activation of ATM/Chk2 and ATR/Chk1 signaling [17], thereby inhibit cde2 and cyclin B1 expression via activation of p53 and cdc $25 \mathrm{C}$
[25]. This may lead to G2/M cell cycle arrest and apoptosis of cells [25] and could partly explain the LPC-induced cell cycle arrest, apoptosis and the suppression of cdc 2 and cyclin B1 expression in endothelial cells in this study.

The above event is related to the induction of ROS over-production by LPC. Recently oleoyl-LPC has been shown to cause a decrease of NO production, and eNOS uncoupling, but increase of ROS production in EAHY endothelial cells [13]. Peng et al. (2010) also found the inhibition of NO, stimulation of ROS by LPC to stimulate caspase 3-dependent apoptotic response in endothelial cells [10]. Similarly we also found the over-production of ROS of endothelial cells by LPC, suggesting its involvement in LPC-induced toxic events. Accordingly LPC is shown to stimulate over-production of NO and ROS to mediate its toxic injury to endothelial cells (HUVEC) [12]. LPC stimulates superoxide production of HUVEC endothelial cells through activation of NADPH oxidase to stimulate cell proliferation $[14,15]$.

Vascular inflammation is important in the pathogenesis of atherosclerosis and other cardiovascular
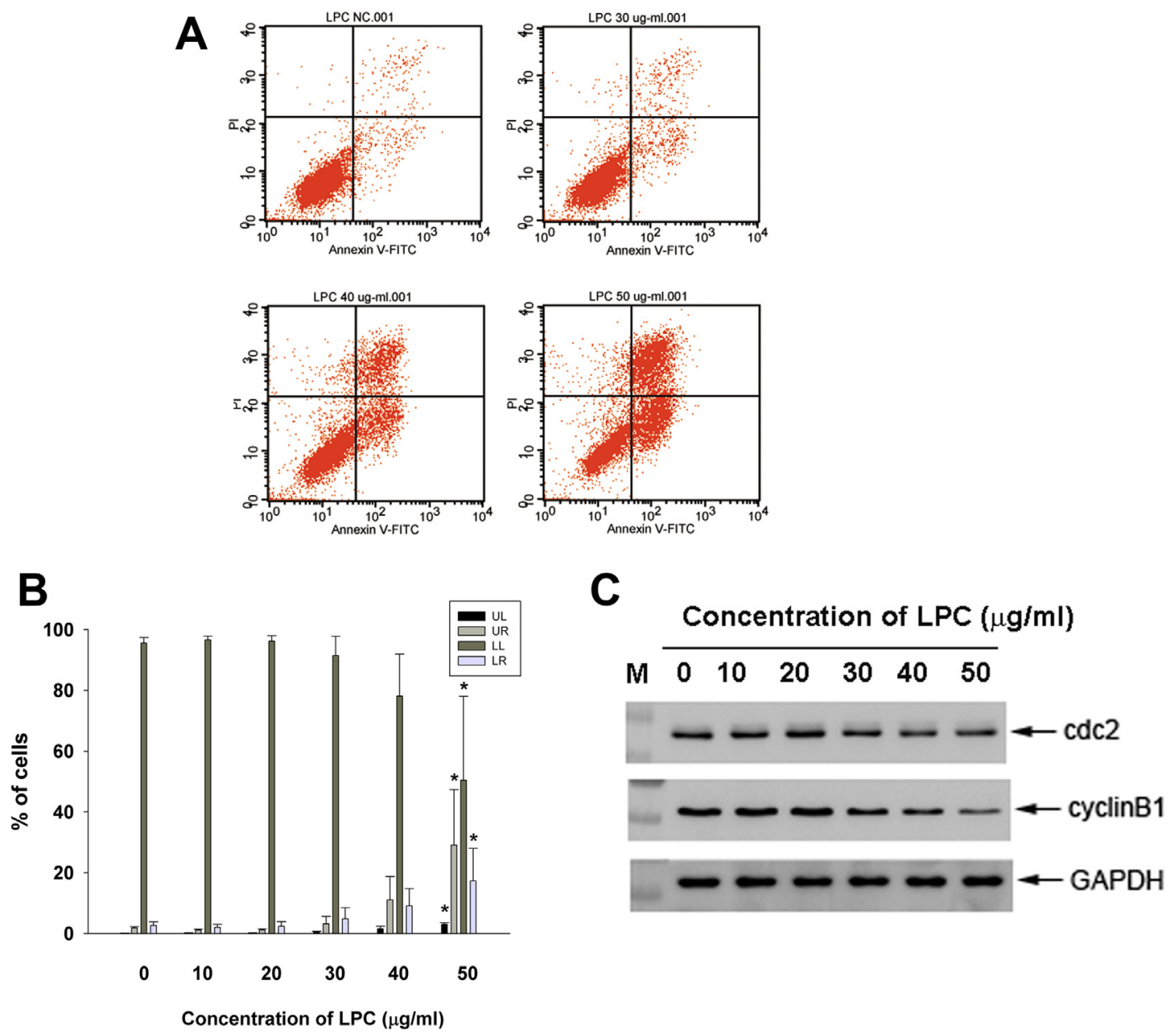

Figure 3: Effect of LPC on apoptosis of EAHY endothelial cells as analyzed by PI and annexin V dual fluorescent flow cytometry. (A) One representative flow cytometry picture was shown. (B) Quantitative analysis of PI + annexin V flow cytometric analysis. "denotes statistically significant difference $(p<0.05)$ when compared with control $(\mathbf{C})$ Effect of LPC on cdc2, and cyclin B1 protein expression of EAHY cells. One representative western blot picture was shown. Expression of GAPDH was used as control. 
diseases [26, 27]. Local production of chemokines such as IL-8 and MCP-1 may lead to inflammatory cells infiltration in the vascular intima that is important to the initiation and progression of atherosclerosis, heart disease and stroke [28]. In this study, LPC induced IL-8 production and mRNA/protein expression in EAHY endothelial cells. Similarly, LPC is also shown to stimulate IL-6 and IL-8 production of umbilical vein endothelial cells via a sterol regulatory element binding protein-2-independent manner [9]. This is partly due to activation of G-protein coupled receptor, but not platelet activating factor receptor [29]. LPC-induced tissue inflammation (MCP-1, IL-6 secretion) and cytotoxicity to HUVEC is related to notch signaling and g-secretase activity [8]. All these results suggest the involvement of LPC-induced vascular inflammation in vascular diseases.
A

Control p-ATM

B p-ATR

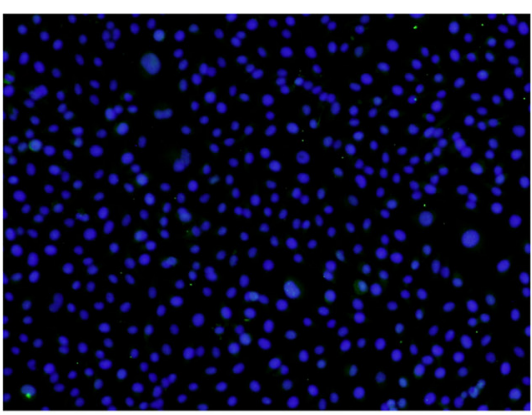

LPC $(50 \mu \mathrm{g} / \mathrm{ml})$
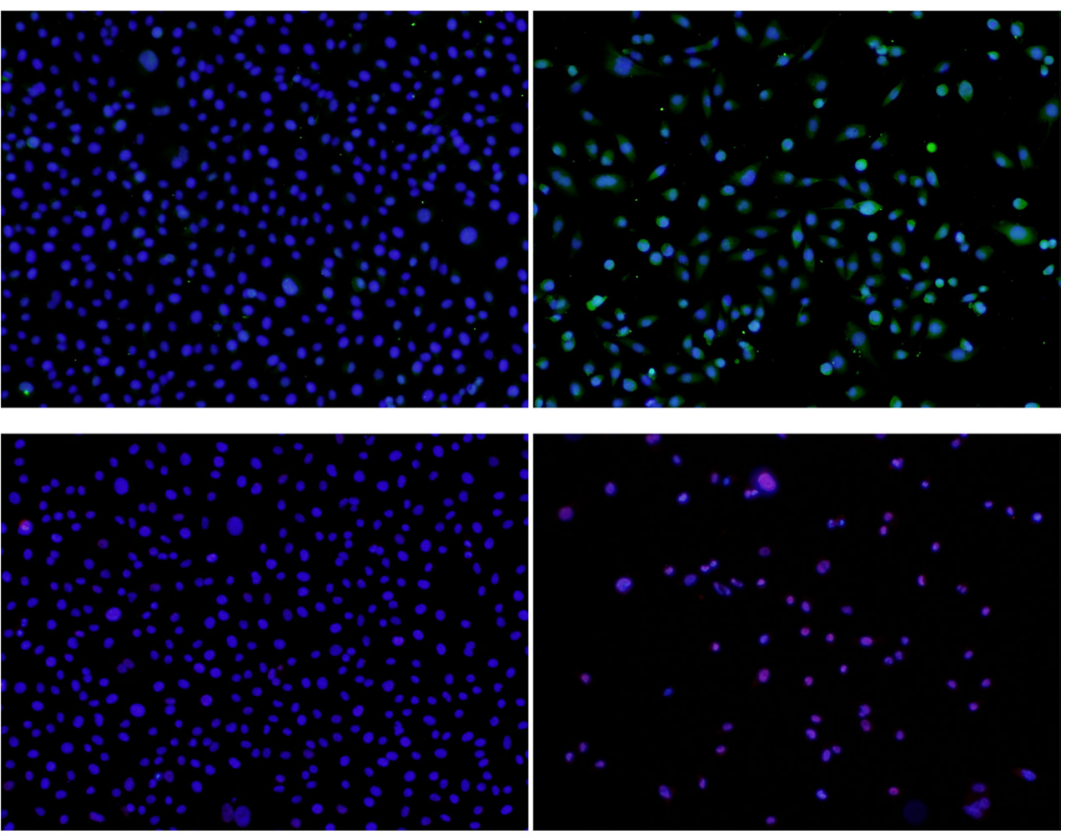

C

p-Chk1
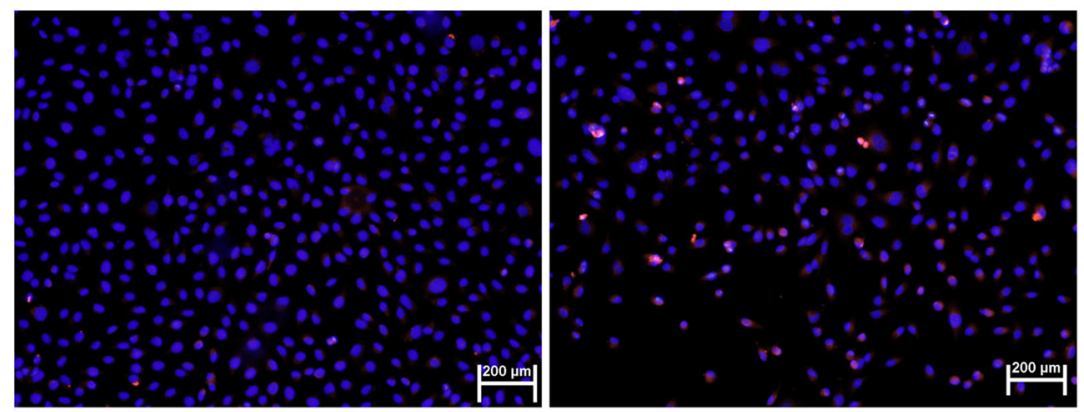

D

p-Chk2
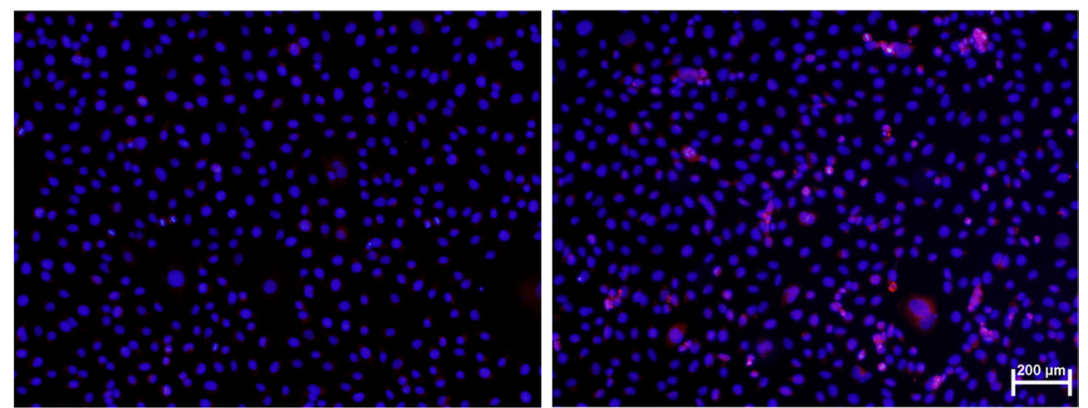

Figure 4: Induction of p-ATM, p-ATR, p-Chk1, and p-Chk2 expression by LPC to endothelial cells. EAHY endothelial cells were exposed to different concentrations of LPC. Immunofluorescent (IF) microscopic observation was utilized to determine the expression of (A) p-ATM, (B) p-ATR, (C) p-Chk1, and (D) p-Chk2 in endothelial cells. One representative IF picture was shown. (blue DAPI, green - p-ATM, red - p-ATR, p-Chk1, or p-Chk2). 
LPC has been shown to stimulate Akt signaling pathway to up-regulate the production of extracellular matrix proteins such as biglycan, and type I collagen in human aortic valve cells [30]. But this effect of LPC is not mediated by MEK/ERK signaling [30]. These effects by LPC may contribute to valve sclerosis as well as aortic stenosis [30]. Limited information is known about the effect of LPC on PI3K/Akt signaling of endothelial cells. LPC is shown to stimulate Sp1 binding and endothelial nitric oxide synthase (eNOS) promoter activity in endothelial cells via G-protein and PI3K-JAK2-MEKERK signaling pathways, but unrelated to Ras and Raf [31]. LPC may stimulate MEK/ERK, Akt and p38 in endothelial cells, but it also inhibits EGF-induced activation of Akt $[29,32]$. In this study, we found that LPC induced Akt phosphorylation/activation of endothelial cells. Moreover, LY294002 prevented the LPC-induced apoptosis and IL-8 production/expression of endothelial cells, implicating the crucial role of PI3K/Akt signaling in LPC-induced apoptotic and inflammatory response in vascular endothelium.

In conclusion, these results indicate that LPC may contribute to the pathogenesis of atherosclerosis and other cardiovascular diseases by inducing the cytotoxicity, cell cycle arrest and apoptosis of endothelial cells. These
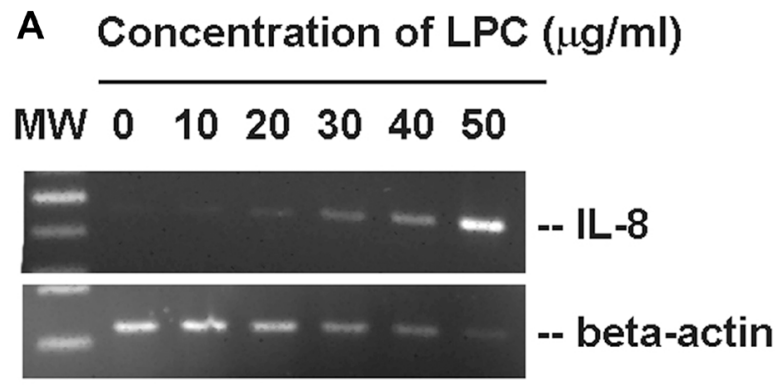

events are related to ROS production, activation of ATM/Chk2, ATR/Chk1, PI3K/Akt and the inhibition of cdc2 and cyclin B1 expression. LPC may also induce vascular inflammation by stimulation of IL-8 production and expression of endothelial cells through activation of PI3K/Akt signaling. These results can be helpful for our understanding the physiological and toxicological effect of LPC on the health of cardiovascular system, the underlying signal transduction mechanisms and future disease prevention.

\section{MATERIALS AND METHODS}

\section{Materials}

\section{3-(4,5-dimethylthiazol-2-yl)-2,5-diphenyl}

tetrazolium bromide (MTT), DCFH-DA and dimethylsulfoxide (DMSO) were purchased from Sigma/ Aldrich Chemical Company (St. Louis, MO, USA). LPC and LY294002 were purchased from Cayman (Cayman Chemical Company, Ann Arbor, MI, USA). Cell culture biologicals (Dulbecco's modified Eagle's medium [DMEM], fetal bovine serum [FBS], trypsin/EDTA etc) were obtained from Life Technologies (Grand Island, New York, USA). Eahy926 (EAHY) endothelial cells were

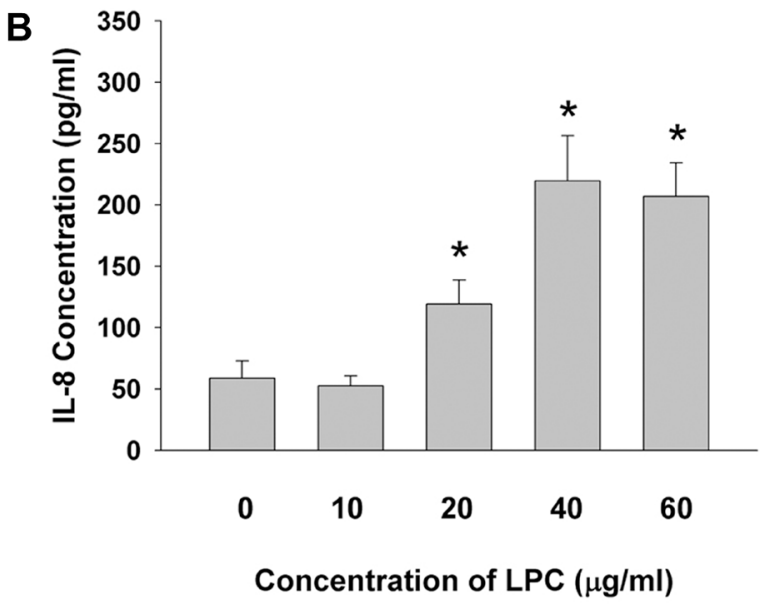

\section{LPC Concentration}

\section{$\begin{array}{llllllll}\text { MW } & 0 & 20 & 30 & 40 & 50 & 60 & (\mu \mathrm{g} / \mathrm{ml})\end{array}$}

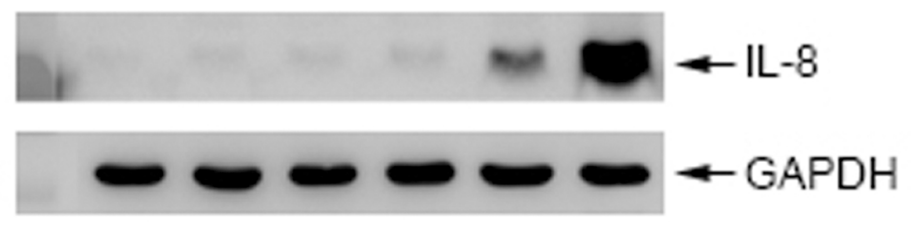

Figure 5: Effect of LPC on IL-8 expression and production. EAHY endothelial cells were exposed to LPC. (A) Total RNA was isolated and subjected to RT-PCR analysis of IL-8 expression, (B) Culture medium was collected and used for measurement of IL-8 secretion in endothelial cells. (C) Western blotting of IL-8 protein expression after exposure of endothelial cells to LPC for 24 hours. One representative result was shown. 
given by Professor Cora-Jean S. Edgell (North Carolina University, NC, USA) and characterized to express endothelial cell markers such as factor VIII-related antigens and von Willebrand factor [33] and studied in my laboratory before $[34,35]$. They were cultured in DMEM containing 10\% FBS. Specific PCR primers were synthesized by MDBio Inc. (Taipei, Taiwan). Antibodies against cdc2 (sc-54), cyclin B1 (sc-245), p-ATM (Ser1981, sc-47739), p-ATR (Ser428, sc-109912), p-Chk1 (Ser345, sc-17922), p-Chk2 (Thr68, sc-16297-R), p-Akt 1/2/3 (Ser473, sc-514032) and glyceraldehtde 3-phosphate dehydrogenase (GAPDH) (sc-32233) were obtained from Santa Cruz (Santa Cruz Biotechnology, Dallas, TX, USA).

A Control $=101$

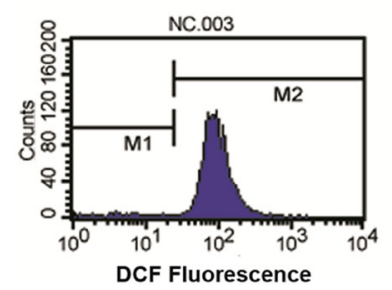

$\mathrm{LPC} 40 \mathrm{ug} / \mathrm{ml}=124$

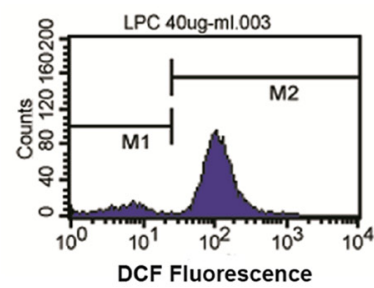

Enzyme-linked immunosorbant assay (ELISA) kits for IL-8 were purchased from PeproTech (Rocky Hill, NJ, USA). RT and PCR kits were from Zimeset Biotech Co. Ltd, Taipei, Taiwan. Annexin V-FITC and isotype control were from eBioscience (San Diego, CA, USA).

\section{Cytotoxicity of LPC on endothelial cells}

Briefly, $5 \times 10^{5}$ EAHY cells were seeded onto 6-well culture plates. After $24 \mathrm{~h}$, culture medium was changed and then various amounts of LPC $(10-50 \mu \mathrm{g} / \mathrm{ml})$ were added. Cells are further incubated for 3 days. Culture medium was collected for ELISA. Then fresh medium

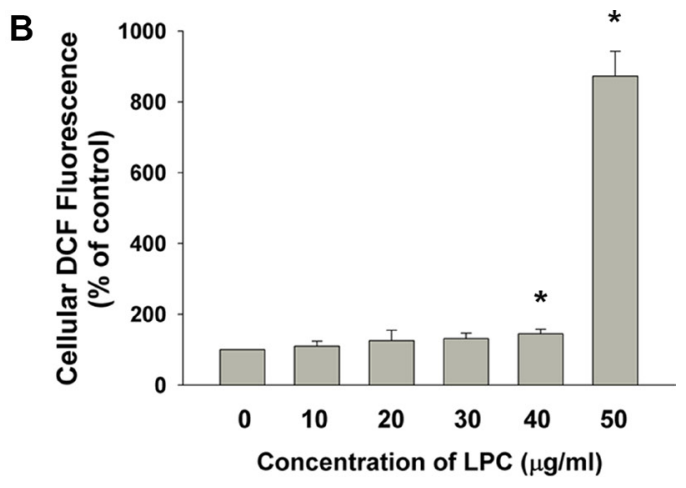

\section{c p-Akt}

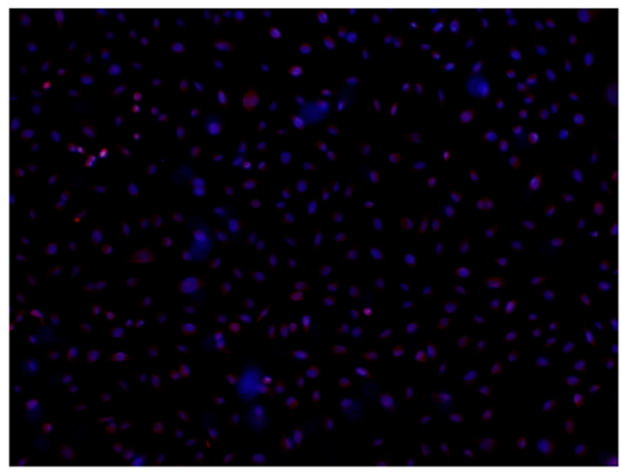

\section{Control}

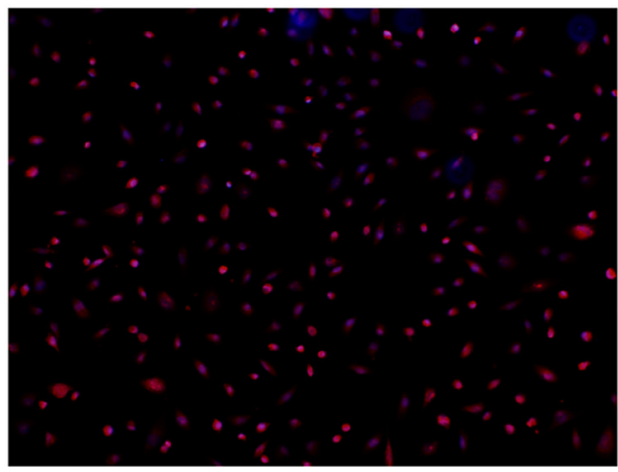

\section{LPC}

Figure 6: Effects of LPC on cellular ROS levels and Akt phosphorylation. (A) LPC stimulated ROS production as revealed by an increase in cellular DCF fluorescence. One representative DCF flow cytometry picture was shown, (B) Quantitative results of DCF fluorescence. Results were expressed as Mean \pm SE ( $\%$ of control), "denotes statistically significant difference $(p<0.05)$ when compared with control, (C) LPC induced Akt activation as indicated by an increase in cellular p-Akt fluorescence (blue - DAPI, red - p-Akt). One representative IF picture was shown. 
containing MTT (final $0.5 \mathrm{mg} / \mathrm{ml}$ ) was added into each well and cells were cultured for further $2 \mathrm{~h}$. The insoluble formazan generated by viable cells was dissolved in DMSO and read against reagent blank (DMSO) at a wavelength of $540 \mathrm{~nm}$ by a microplate reader (BioTech Instruments Inc., VM, USA) as before for estimation of cell viability [36-38]. Results were expressed as Mean \pm SE (\% of control).

\section{Effect of LPC on cell cycle progression}

Briefly $5 \times 10^{5}$ EAHY were seeded onto 6-well culture plates. After $24 \mathrm{~h}$, culture medium was changed and then various amounts of LPC (final 10, 20, 30, 40, $50 \mu \mathrm{g} / \mathrm{ml}$ ) were added. Cells were further incubated for 3 days. Alterations in the cell cycle distribution of endothelial cells were investigated by propidium iodide (PI) staining of DNA contents by flow cytometry [36-38]. Briefly, both floating and attached cells were collected together, re-suspended and fixed for $30 \mathrm{~min}$ in $70 \%$ ice-cold ethanol including RNase $(2 \mathrm{mg} / \mathrm{ml})$. Cells were then washed with phosphate-buffered saline (PBS) and finally stained with PI $(40 \mu \mathrm{g} / \mathrm{ml})$ for 10 min. The PI-elicited fluorescence of individual cell was measured by a FACSCalibur Flow Cytometer (Becton Dickinson, Worldwide Inc., San-Jose, CA, USA). The wavelength of laser excitation was set at $488 \mathrm{~nm}$ and the emission collected was set at greater than $590 \mathrm{~nm}$. The FL2 fluorescence was collected in a linear/log scale fashion. A total of 10,000 cells were analyzed for each sample. The percentage of cells residing in $\mathrm{G}_{0} / \mathrm{G}_{1}$ phase, $\mathrm{S}$ phase, $\mathrm{G}_{2} / \mathrm{M}$ and sub- $\mathrm{G}_{0} / \mathrm{G}_{1}$ phase were measured using standard ModiFit software and CELL QUEST programs.
A Control
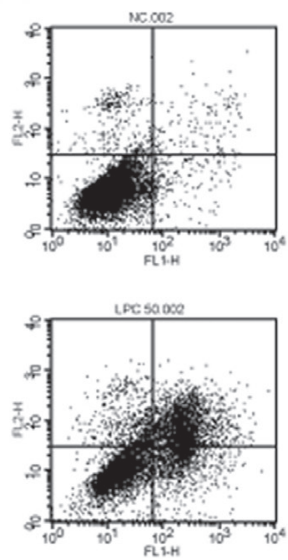

LPC $50 \mu \mathrm{g} / \mathrm{ml}$
LY294002 $20 \mu \mathrm{M}$
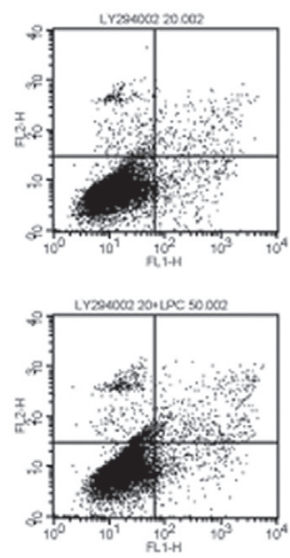

LY294002 + LPC $50 \mu \mathrm{g} / \mathrm{ml}$
B

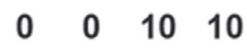

2020 LY294002 ( $\mu \mathrm{M})$

$\begin{array}{llllllll}\text { MW } & 0 & 50 & 0 & 50 & 0 & 50 & \mathrm{LPC}(\mu \mathrm{g} / \mathrm{ml})\end{array}$

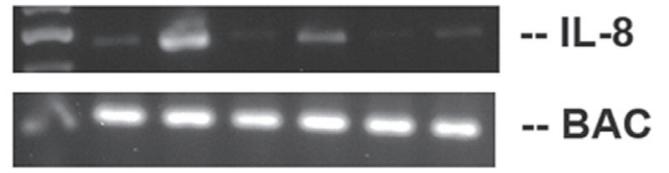

C $\begin{array}{cccccccl} & 0 & 0 & 10 & 10 & 20 & 20 & \operatorname{LY} 294002(\mu \mathrm{M}) \\ \text { MW } & 0 & 50 & 0 & 50 & 0 & 50 & \operatorname{LPC}(\mu \mathrm{g} / \mathrm{ml})\end{array}$

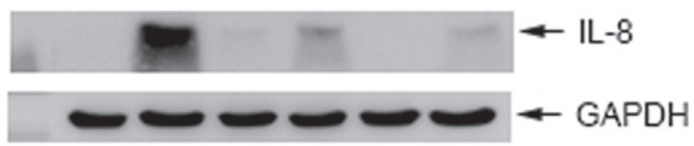

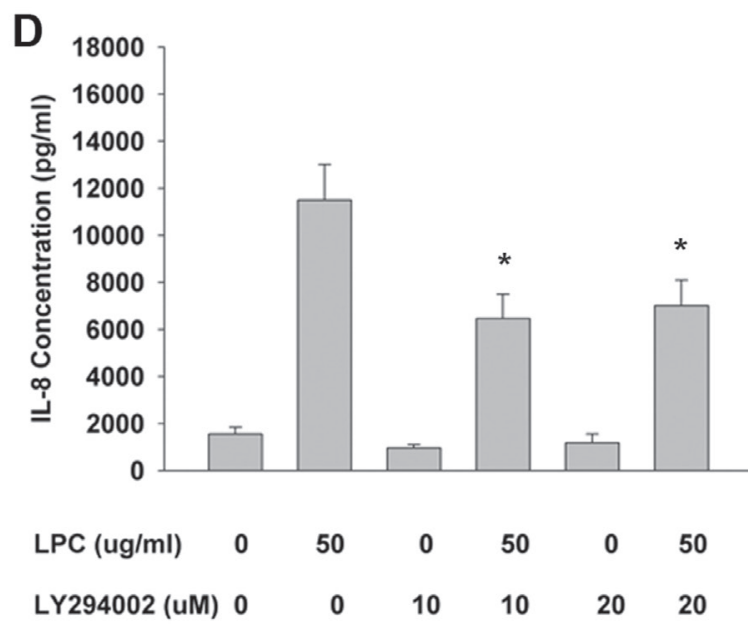

Figure 7: Effect of LY294002 on LPC-induced apoptosis and IL-8 expression/ secretion. (A) LY294002 prevented the LPCinduced apoptosis of endothelial cells as revealed by PI+Annexin V dual staining flow cytometry. One representative result was shown. (B) LY294002 prevented the LPC-induced IL-8 expression of endothelial cells, (C) LY294002 prevented the LPC-induced IL-8 protein expression of endothelial cells as analyzed by western blot, (D) LY294002 attenuated the LPC-induced IL-8 secretion of endothelial cells as analyzed by ELISA. "denotes statistically significant difference when compared with LPC $50 \mathrm{mg} / \mathrm{ml}$ group. 
Assay the effect of LPC on apoptosis of endothelial cells - PI+Annexin V dual fluorescent flow cytometry

Endothelial cells $\left(5 \times 10^{5}\right.$ cells $)$ were seeded and treated by various concentration of LPC for 24 hours. Then both floating and attached cells were harvested. Cells were then washed with PBS, resuspended in $400 \mu \mathrm{l}$ HEPES (10 mM HEPES-NaOH, pH 7.4, $140 \mathrm{mM} \mathrm{NaCl}$, $2.5 \mathrm{mM} \mathrm{CaCl}_{2}$ ) solution, and the Annexin V-FITC (Becton Dickson)/ PI (50 $\mu \mathrm{g} / \mathrm{ml})$ staining solution was added in the dark for 30 min. The Annexin V-FITC and PI fluorescence of cultured cells were analyzed by FACSCalibur Flow Cytometry (Becton Dickinson) immediately as described before [36]. In each analysis, 15,000 events will be recorded.

\section{Reverse transcriptase-polymerase chain reaction (RT-PCR)}

Generally $1.5 \times 10^{6}$ EAHY cells were inoculated onto $10-\mathrm{cm}$ culture dishes and exposed to LPC for $24 \mathrm{~h}$. Total RNA was isolated and subjected for analysis of IL-8 and beta-actin genes expression by RT-PCR procedures as before $[36,37]$. In brief, RNA was reverse transcribed for generation of cDNA and the same amounts of cDNA were used for PCR amplification in a reaction mixture composing $5 \mu$ of 10x Super TAQ buffer, $4 \mu 1$ of $2.5 \mathrm{mM}$ dNTP, $1 \mu \mathrm{l}$ of each specific primer, $0.2 \mathrm{ml}$ of Super TAQ enzyme $(2 \mathrm{U} / \mu \mathrm{l})$, and double distilled water. The nucleotide sequence of PCR primers were BAC: AAGAGAGGCATCCTCACCCT and TACATGGCTGGGGTGTTGAA (218 bp), and IL-8: CACAAGAGCCAGGAA GAAAC and CACAAGAGCCAGGAAGAAAC (459 bp) [35]. The amplification steps for the studied genes included 20-35 cycles of PCR, denaturing at $94^{\circ} \mathrm{C}$ for $1 \mathrm{~min}$, annealing at $55^{\circ} \mathrm{C}$ for $1 \mathrm{~min}$, and extension at $72^{\circ} \mathrm{C}$ for $1 \mathrm{~min}$. This was followed by a final extension at $72^{\circ} \mathrm{C}$ for $7 \mathrm{~min}$. The PCR amplified products were loaded into $1.8 \%$ agarose gel electrophoresis, and DNA bands were stained with ethidium bromide for photograph taking.

\section{Western blotting}

Generally $1.5 \times 10^{6}$ EAHY were inoculated onto 10 $\mathrm{cm}$ culture dishes and exposed to various concentrations of LPC for $24 \mathrm{~h}$. After removal of medium and washed with PBS, cell lysates were prepared by dissolving cells in lysis buffer $(10 \mathrm{mM}$ Tris- $\mathrm{HCl}, \mathrm{pH} 7 ; 140 \mathrm{mM}$ sodium chloride; $3 \mathrm{mM}$ magnesium chloride; $0.5 \% \mathrm{NP}-40 ; 2$ $\mathrm{mM}$ phenylmethylsulfonyl fluoride; $1 \%$ aprotinin; and 5 $\mathrm{mM}$ dithiothreitol). Then the equal amounts of proteins $(20-50 \mu \mathrm{g} / \mathrm{ml})$ were loaded to run $12.5 \%$ sodium dodecyl sulfate-polyacrylamide gel electrophoresis (SDS-PAGE) for protein separation and transferred to a polyvinylidene fluoride (PVDF) membrane. The membranes were first blotted with primary antibodies of cdc2, cyclin B1, IL-8 and GAPDH for $2 \mathrm{hr}$ as described before [35, 36]. The membranes were then incubated in respective horseradish peroxidase-link secondary antibodies (Jackson ImmunoResearch Laboratories, West Grove, PA, USA) for $1 \mathrm{hr}$. After washing the membrane with buffer, ECL reagents (Amersham) were added and the chemiluminescence of protein bands was determined by exposure of membranes to Fuji films for $30 \mathrm{sec}$ to $10 \mathrm{~min}$. The intensity of GAPDH bands was used as control.

\section{Effect of LPC on IL-8 production of endothelial cells as analyzed by ELISA}

In short, $5 \times 10^{5}$ EAHY cells were inoculated onto 6-well culture plates. After $24 \mathrm{~h}$, culture medium was changed with fresh medium containing various amounts of LPC (final concentrations of 10, 20,30,40,50 mg/ml) for 3 days. Culture medium was collected for analysis of IL- 8 by ELISA following the instruction of assay kits [35, $37,39,40]$.

\section{Effect of LPC on cellular ROS levels}

Briefly $5 \times 10^{5}$ EAHY were seeded onto 6-well culture plates. After $24 \mathrm{~h}$, culture medium was changed and then various amounts of LPC (final 10, 20, 30, 40, $50 \mathrm{mg} / \mathrm{ml}$ ) were added. Cells were further incubated for 3 days and then stained with $10 \mu \mathrm{M}$ DCFH-DA for 30 minutes. Both floating and attached cells were collected and pulled together. Cells were re-suspended in $200 \mu \mathrm{l}$ of PBS and the DCF-elicited fluorescence of cells was determined by FACS Calibur Flow Cytometry (Becton Dickinson, Worldwide Inc., San-Jose, CA, USA) [35, 36]. Totally 10000 cells were analyzed for all the samples. The mean of DCF fluorescence was counted by the CELL Quest program (Becton Dickinson, CA, USA).

\section{Activation of ATM, ATR, chk1, chk2 and akt by LPC}

EAHY cells $\left(1 \times 10^{5}\right)$ were seeded onto 24 -well culture plate with sterile coverslips in $1 \mathrm{ml}$ DMEM with $10 \%$ FBS. After $24 \mathrm{~h}$, culture medium was changed and then various amounts of LPC (final 10, 20, 30, 40, $50 \mu \mathrm{g} / \mathrm{ml}$ ) were added. Cells were further incubated for 24 hours or different time points. Then medium was removed, and cells were washed with PBS and fixed in $4 \%$ paraformaldehyde for 20 minutes. Cells were further washed with PBS, permeabilized with $2 \%$ Triton X-100, exposed to $0.3 \% \mathrm{v} / \mathrm{v}_{2} \mathrm{O}_{2}$ for 20 minutes. After rinsed with PBS, 5\% bovine serum albumin (BSA) was used for blocking cells for 1 hour and then cells were incubated 
with primary antibodies (p-ATM, p-ATR, p-Chk1, p-Chk2, p-Akt) $(1: 1000, \mathrm{v} / \mathrm{v})$ at room temperature for overnight. Following washed by PBS, cells were incubated in respective secondary antibodies (FITCconjugated for $\mathrm{p}$-ATM, and TRITC-conjugated for $\mathrm{p}$-ATR, p-Chk1, p-Chk2 and p-Akt) in the dark for 1 hour and counterstained the nucleus with DAPI $(1: 1000)$ for 30 min. Finally the cells in coverslips were mounted and photographed/observed under an inverted microscope and DP Controller/Manager software (Olympus IX71, Olympus Corporation) $[35,36,38]$.

\section{Role of PI3K/Akt signal transduction pathway in LPC-induced changes of endothelial cells}

To know the role of PI3K/Akt signaling, EAHY endothelial cells $\left(5 \times 10^{5}\right.$ cells/well, in 6 -well plate $)$ were pretreated by LY294002 (10/20 $\mu \mathrm{M}$, a PI3K/Akt signaling inhibitor) or DMSO for $30 \mathrm{~min}$ prior the addition of LPC, and cells were further co-incubated for 3 days. Cellular apoptosis was measured by PI/Annexin V dual fluorescent flow cytometry as described above. IL-8 mRNA expression, protein expression and secretion were studied by RT-PCR, western blotting and ELISA, respectively, as described above.

\section{Statistical analysis}

Three or more separate experiments were conducted. The results were analyzed by paired Students $t$-test. A $p$ value $<0.05$ was considered to have a statistically significant difference between groups. In some experiments, $50 \%$ inhibitory concentration (IC50) of LPC was calculated by Regression analysis.

\section{CONFLICTS OF INTEREST}

None.

\section{FUNDING}

This study is supported by Chang Gung Memorial Hospital (CMRPF3E0021, CMRPF3E0022, CMRPF3E0023, CMRPF1G0101, NMRPF3C0091, NMRPF3C0061, CMRPG1B0031, CMRPF170053, NMRPF370033, CMRPF3E0021, NMRPF3B0071, NMRPF3E0041, NMRPF3C0093, CMRPF1C0011, 1C0012; NMRPF3C0092, NMRPF3C0062, NMRPF3E0043, NMRPF3E0042) and Ministry of Science and Technology, Taiwan (NSC1022314-B-255-003-MY2, NSC102-2628-B-255-001-MY3, NSC101-2320-B-255-002, NSC-100-2314-B-002-094, NSC-101-2320-B-255-002, and MOST 104-2314-B-255010-MY3 MOST106-2314-B-002-034-MY2, MOST1062314-B002-033-MY2) and National Taiwan University Hospital (NTUH 101-001937, NTUH102-002259, NTUH101-S1862 \& NTUH102-S2180, NTUH103-S2368, NTUH104-S2658, NTUH106-S3467, NTUH106-UN-001).

\section{REFERENCES}

1. Hasegawa H, Lei J, Matsumoto T, Onishi S, Suemori K, Yasukawa M. Lysophosphatidylcholine enhances the suppressive function of human naturally occurring regulatory $\mathrm{T}$ cells through TGF-b production. Biochem Biophys Res Commun. 2011; 415:526-531.

2. Hughs H, Mathews B, Lenz ML, Guyton JR. Cytotoxicity of oxidized LDL to porcine aortic smooth muscle cells is associated with the oxysterols 7-ketocholesterol and 7-hydroxycholesterol. Arterioscler Thromb. 1994; 14:1177-1185.

3. Drzazga A, Sorinska A, Koziolkiewicz M. Lysophosphatidylcholine and lysophosphatidylinositol -novel promising signaling molecules and possible therapeutic activity. Acta Pol Pharm. 2014; 71:887-899.

4. Wang Y, Wang Y, Li GR. TRPC1/TRPC3 channels mediate lysophosphoatidylcholine- induced apoptosis in cultured human coronary smooth muscle cells. Oncotarget. 2016; 7:50937-50951. https://doi.org/10.18632/oncotarget.10853.

5. Kougias P, Chai H, Lin PH, Lumsden AB, Yao Q, Chen C. Lysophosphatidylcholine and secretory phospholipase A2 in vascular disease: mediators of endothelial dysfunction and atherosclerosis. Med Sci Monit. 2006; 12:5-16.

6. Canning P, Kenny BA, Price V, Glenn J, Sarker MH, Hudson N, Brandt M, Lopez FJ, Gale D, Luthert PJ, Adamson P, Turowski P, Stitt AW. Lipoprotein-associated phospholipase A2 (Lp-PLA2) as a therapeutic target to prevent retinal vasopermeability during diabetes. Proc Natl Acad Sci USA. 2016; 113:7213-7218.

7. Lee YW, Kim PH, Lee WH, Hirani AA. Interleukin-4, oxidative stress, vascular inflammation and atherosclerosis. Biomol Ther. 2010; 18:135-144.

8. Zhao J, Liang Y, Song F, Xu S, Nian L, Zhou X, Wang S. TSG attenuates LPC-induced endothelial cells inflammatory damage through notch signaling inhibition. IUBMB Life. 2016; 68:37-50.

9. Morita M, Sekine A, Urano Y, Nishimura T, Takabe W, Arai H, Hamakubo T, Kodama T, Noguchi N. Lysophosphatidylcholine promotes SREBP-2 activation via rapid cholesterol efflux and SREBP-2-independent cytokine release in human endothelial cells. J Biochem. 2015; 158:331-338.

10. Peng ZY, Zhang SD, Liu S, He BM. Protective effect of neferine on endothelial cell nitric oxide production induced by lysophosphatidylcholine: the role of the DDAH-ADMA pathway. Can J Physiol Pharmacol. 2011; 89:289-294.

11. Suzuki M, Minami A, Nakanishi A, Kobayashi K, Matsuda S, Ogura Y, Kitagishi Y. Atherosclerosis and tumor suppressor molecules (review). Int J Mol Med. 2014; 34:934-940.

12. Kim EA, Kim JA, Park MH, Jung SC, Suh SH, Pang MG, Kim YJ. Lysophosphatidylcholine induces endothelial cell injury by nitric oxide production through oxidative stress. J Matern Fetal Neonatal Med. 2009; 22:325-331. 
13. Kozina A, Opresnik S, Wong MS, Hallstrom S, Graier WF Malli R, Schroder K, Schmidt K, Frank S. Oleoyllysophosphatidylcholine limits endothelial nitric oxide bioavailability by induction of reactive oxygen species. PLoS One. 2014; 9:e113443.

14. Heinloth A, Heermeier K, Raff U, Wanner C, Galle J. Stimulation of NADPH oxidase by oxidized low-density lipoprotein induces proliferation of human vascular endothelial cells. J Am Soc Nephrol. 2000; 11:1819-25.

15. Galle J, Heinloth A, Wanner C, Heermeier K. Dual effect of oxidized LDL on cell cycle in human endothelial cells through oxidative stress. Kidney Int. 2001; 78:S120-3.

16. Shimizu R, Kanno K, Sugiyama A, Ohata H, Araki A, Kishikawa N, Kimura Y, Yamamoto H, Kodama M, Kihira K, Tazuma S. Cholangiocyte senescence caused by lysophosphatidylcholine as a potential implication in carcinogenesis. J Hepathobiliary Pancreat Sci. 2015; 22:675-82.

17. Yan S, Sorrell M, Berman Z. Functional interplay between ATM/ATR-mediated DNA damage response and DNA repair pathways in oxidative stress. Cell Mol Life Sci. 2014; 71:3951-3967.

18. Garcia V, Lara-Chica M, Cantarero I, Sterner O, Calzado MA, Munoz E. Galiellalactone induces cell cycle arrest and apoptosis through the ATM/ATR pathway in prostate cancer cells. Oncotarget. 2016; 7:4490-4506. https://doi. org/10.18632/oncotarget.6606.

19. Yang J, Zhao X, Tang M, Li L, Lei Y, Cheng P, Guo W, Zheng Y, Wang W, Luo N, Peng Y, Tong A, Wei Y, et al. The role of ROS and subsequent DNA-damage response in PUMA-indued apoptosis of ovarian cancer cells. Oncotarget. 2017; 8:23492-23506. https://doi.org/10.18632/ oncotarget. 15626.

20. Hidalgo MA, Carretta MD, Teuber SE, Zarate C, Carcamo L, Concha II, Burgos RA. fMLP-induced IL-8 release is dependent on NADPH oxidase in human neutrophils. J Immunol Res. 2015; 120348.

21. Sun Y, Lee JH, Kim NH, Lee CW, Kim MJ, Kim SH, Huh SO. Lysophosphatidylcholine-induced apoptosis in H19-7 hippocampal progenitor cells is enhanced by the upregulation of Fas ligand. Biochim Biophys Acta. 2009; 1791:61-68.

22. Zhou L, Shi M, Guo Z, Brisbon W, Hoover R, Yang H. Different cytotoxic injuries induced by lysophosphatidylcholine and 7-ketocholesterol in mouse endothelial cells. Endothelium. 2006; 13:213-226.

23. Tsai CH, Hung AC, Chen YY, Chiu YW, Hsish PW, Lee YC, Su YH, Chang PC, Hu SC, Yuan SF. 3'-hydroxy-4'-methoxyb-methyl-b-nitrostyrene inhibits tumorigenesis in colorectal cancer cells through ROS-mediated DNA damage and mitochondrial dysfunction. Oncotarget. 2017; 8:18106-18117. https://doi.org/10.18632/oncotarget.14996.

24. Yin H, Jiang M, Peng X, Cui H, Zhou Y, He M, Zuo Z, Ouyang P, Fan J, Fang J. The molecular mechanism of $\mathrm{G} 2 / \mathrm{M}$ cell cycle arrest induced by AFB1 in the jejunum.
Oncotarget. 2016; 7:35592-35606. https://doi.org/10.18632/ oncotarget.9594.

25. Taylor WR, Stark GR. Regulation of the G2/M transition by p53. Oncogene. 2001; 20:1803-1815.

26. Krishnaswamy G, Kelley J, Yerra L, Smith JK, Chi DS. Human endothelium as a source of multifunctional cytokines: molecular regulation and possible role in human disease. J Interferon Cytokine Res. 1999; 19:91-104.

27. Szelag M, Piaszyk-Borychowska A, Plens-Galaska M, Wesoly J, Bluyssen HA. Targeted inhibition of STATs and IRFs as a potential treatment strategy in cardiovascular disease. Oncotarget. 2016; 7:48788-48812. https://doi. org/10.18632/oncotarget.9195.

28. Braunersreuther V, Mach F, Steffens S. The specific role of chemokines in atherosclerosis. Thromb Haemost. 2007; 97:714-721.

29. Murugesan G, Sandhya Rani MR, Gerber CE, Mukhopadhyay C, Ransohoff RM, Chisolm GM, KottkeMarchant K. Lysophosphatidylcholine regulates human microvascular endothelial cell expressionof chemokines. J Mol Cell Cardiol. 2003; 35:1375-1384.

30. Cheng H, Yao Q, Song R, Zhai Y, Wang W, Fullerton DA, Meng X. Lysophosphatidylcholine activates the Akt pathway to upregulate extracellular matrix protein production in human aortic valve cells. J Surg Res. 2017; 213:243-250.

31. Cieslik K, Abrams CS, Wu KK. Up-regulation of endothelial nitric-oxide synthase promoter by the phosphatidylinositol 3-kinase gamma/Janus kinase 2/MEK-1-dependent pathway. J Biol Chem. 2001; 276:1211-1219.

32. Thors B, Halldorsson H, Clarke GD, Thorgeirsson G. Inhibition of Akt phosphorylation by thrombin, histamine and lysophosphatidylcholine in endothelial cells. Differential role of protein kinase C. Atherosclerosis. 2003; 168:245-253.

33. Edgell CJ, McDonald CC, Graham JB. Permanent cell line expressing human factor VIII-related antigen established by hybridization. Proc Natl Acad Sci USA. 1983; 80:3734-3737.

34. Tseng SK, Chang MC, Su CY, Chi LY, Chang JZ, Tseng WY, Yeung SY, Hsu ML, Jeng JH. Arecoline induced cell cycle arrest, apoptosis and cytotoxicity of human endothelial cells. Clin Oral Invest. 2012; 16:1267-1273.

35. Chang MC, Chen YJ, Liou EJ, Tseng WY, Chan CP, Lin HJ, Liao WC, Chang YC, Jeng PY, Jeng JH. 7-Ketocholesterol induces ATM/ATR, Chk1/Chk2, PI3K/Akt siganling, cytotoxicity and IL-8 production in endothelial cells. Oncotarget. 2016; 7:74473-83. https://doi.org/10.18632/ oncotarget. 12578 .

36. Chang MC, Lin LD, Wu MT, Chan CP, Chang HH, Lee MS, Sun TY, Jeng PY, Yeung SY, Lin HJ, Jeng JH. Effects of camphorquinone on cytotoxicity, cell cycle regulation and prostaglandin E2 production of dental pulp cells: role of ROS, ATM/ATR, MEK/ERK and hemeoxygenase-1. PLoS One. 2015; 10:e143663. 
37. Chang MC, Chan CP, Chen YJ, Hsien HC, Chang YC, Yeung SY, Jeng PY, Cheng RH, Hahn LJ, Jeng JH. Areca nut components stimulate ADAM17, IL-1, PGE2 and 8-isoprostane production in oral keratinocyte: role of reactive oxygen species, EGF and JAK signaling. Oncotarget. 2016; 7:16879-94. https://doi.org/10.18632/ oncotarget.7621.

38. Chang MC, Tsai YL, Liou EJ, Tang CM, Wang TM, Liu HC, Liao MW, Yeung SY, Chan CP, Jeng JH. Effect of butyrate on collagen expression, cell viability, cell cycle progression and related protein expression of MG63 osteoblastic cells. PLoS One. 2016; 11:e0165438.

39. Lin PS, Chang HH, Yeh CY, Chang MC, Chan CP, Kuo HY, Liu HC, Liao WC, Jeng PY, Yeung SY, Jeng JH.
Transforming growth factor beta1 increases collagen content, and stimulates procollagen 1 and tissue inhibitor of metalloproteinase-1 production of dental pulp cells: Role of MEK/ERK and activin receptor-like kinase-5/Smad signaling. J Formos Med Assoc. 2017; 116:351-8.

40. Chang MC, Chang HH, Lin PS, Huang YA, Chan CP, Tsai YL, Lee SY, Jeng PY, Kuo HY, Yeung SY, Jeng JH. Effects of TGF-beta 1 on plasminogen activation in human dental pulp cells: Role of ALK5/Smad2, TAK1 and MEK/ERK signaling. J Tissue Eng Regen Med. 2016 Oct 9. [Epub ahead of print]. 